\title{
Association of socioeconomic and clinical variables with the state of frailty among older inpatients ${ }^{1}$
}

\author{
Darlene Mara dos Santos Tavares² \\ Isabella Danielle Nader ${ }^{3}$ \\ Mariana Mapelli de Paiva ${ }^{4}$ \\ Flavia Aparecida Dias ${ }^{5}$ \\ Maycon Sousa Pegorari ${ }^{5}$
}

\begin{abstract}
Objectives: to identify the prevalence of frailty among inpatient older adults in a clinical hospital and check the association of the socioeconomic and clinical characteristics with the state of frailty. Method: observational, cross-sectional and analytical study, conducted with 255 hospitalized patients. Materials used: structured instrument for the economical and clinical data and frailty phenotype of Fried. Descriptive and bivariate statistical analysis was carried out and, by means of chi-square tests and ANOVA One-way $(p<0.05)$. Results: the prevalence of frailty corresponded to $26.3 \%$, while pre-frailty represented $53.3 \%$. The highest proportion of frail seniors was identified for 80 years or older $(p=0.004)$, widowed $(p=0.035)$ and with the highest average length of stay $(p=0.006)$. Conclusion: inpatient older adults presented high percentages of frail states associated with socioeconomic variables and hospitalization period. The identification of the health conditions related to pre-frailty and frailty can foster the planning and implementation of the assistance to older adults in this context.
\end{abstract}

Descriptors: Frail Elderly; Hospitalization; Elderly; Health Status; Health of the Elderly.

\footnotetext{
${ }^{1}$ Supported by Conselho Nacional de Desenvolvimento Científico e Tecnológico (CNPq), Brazil.

2 PhD, Associate Professor, Departamento de Enfermagem em Educação e Saúde Comunitária, Universidade Federal do Triângulo Mineiro, Uberaba, MG, Brazil.

${ }^{3}$ Undergraduate student in Nursing, Universidade Federal do Triângulo Mineiro, Uberaba, MG, Brazil.

${ }^{4}$ Master's student, Universidade Federal do Triângulo Mineiro, Uberaba, MG, Brazil. Scholarship holder from Coordenação de Aperfeiçoamento de Pessoal de Nível Superior (CAPES), Brazil.

${ }^{5}$ Doctoral student, Universidade Federal do Triângulo Mineiro, Uberaba, MG, Brazil. Sholarship holder from Fundação de Amparo à Pesquisa do estado de Minas Gerais (FAPEMIG), Brazil.
}

Corresponding Author:

Darlene Mara dos Santos Tavares

Universidade Federal do Triângulo Mineiro

Pró-Reitoria de Pesquisa e Pós-Graduação

Av. Frei Paulino, 30

Bairro: Abadia

CEP: 38025-180, Uberaba, MG, Brasil

E-mail: darlenetavares@enfermagem.uftm.edu.br
Copyright () 2015 Revista Latino-Americana de Enfermagem This is an Open Access article distributed under the terms of the Creative Commons Attribution Non-Commercial License (CC BY-NC).

This license lets others distribute, remix, tweak, and build upon your work non-commercially, and although their new works must also acknowledge you and be non-commercial, they don't have to license their derivative works on the same terms. 


\section{Introduction}

Population aging may cause implications to older adults, considering the emergence of significant health problems, especially the condition of frailty ${ }^{(1)}$. This syndrome, of clinical and multidimensional nature, is characterized by increased vulnerability to stressors, with decreased strength, resistance and physiological function; with consequent risk of adverse health events, such as dependency, hospitalization, institutionalization and mortality ${ }^{(2-5)}$.

This issue has been reported in international(3-6) and national literature ${ }^{(7)}$, in studies with the older community and among hospitalized individuals ${ }^{(8-10)}$.

In older surgical populations, frailty represents a risk factor, regardless of the postoperative complications and hospitalization period(11). A study conducted in India, with older patients, identified that $33.2 \%$ were frail $^{(8)}$. A survey carried out in Italy, in geriatric and hospitals institutions, with patients that are 65 years or older, noted greater frailty among 80 years or older, women, illiterates and widowers ${ }^{(12)}$.

In Brazil, there is a lack of studies involving the frailty syndrome in the tertiary service level. In the city of Ribeirão Preto, state of São Paulo, Brazil, a research conducted in a clinical hospital unit showed that $42.9 \%$ of older adults presented severe frailty, higher percentage of women $(63.6 \%)$, 80 years or older (63\%), without partner $(53.1 \%)$ and self-perception of bad health $(75.8 \%)^{(10)}$. Another study conducted in first-aid room of a hospital in the city of Passo Fundo, state of Rio Grande do Sul, Brazil, found a prevalence of $49.5 \%$ of pre-frail older adults and $46.5 \%$ of frail seniors, however, factors statistically associated with the frailty syndrome have not been identified( ${ }^{(9)}$.

Thus, studies that identify older adults in pre-frailty and frailty conditions in hospitals, especially among the Brazilian population, are relevant, as well as to identify their relationship with the socioeconomic, clinic and health variables, considering the high prevalence of the syndrome in this scenario. In this research, the object of study was the age range recommended for developing countries and in Brazil, which considers older adults people above 60 years, unlike research conducted in Brazil, with people above 65 years residents of the community ${ }^{(7)}$.

The deepening in the understanding of this syndrome, in this context, can contribute to early identification, decision making and management of prefrail and frail older adults in the hospital clinical practice, in addition to subsidizing the implementation of public policies. Thus, the objectives were: to identify the prevalence of frailty among older inpatients in a clinical hospital and check the association of the socioeconomic and clinical characteristics with the state of frailty.

\section{Methods}

Cross-sectional, analytical and observational study, conducted with older adults hospitalized in the medical and surgical clinic of the Hospital de Clínicas (HC) of the Universidade Federal do Triângulo Mineiro (UFTM), city of Uberaba, state of Minas Gerais, Brazil. This research is part of a larger project, entitled Study of Frailty in Older Adults (EFRAGI), developed by the Public Health Research Group from UFTM.

For the calculation of the sample size, we considered the prevalence of frailty of $30.0 \%$, analyzing other studies with older adults in hospitals $(33.2 \%)^{(8)}(27 \%)$ (13). With $5 \%$ of accuracy and $95 \%$ of confidence interval, for a finite population of 1455 eligible older adults, a sample of 265 seniors was collected. Considering a sample loss of $50 \%$, the maximum number of interview attempts was 530 . The recruitment process occurred by systematic random sampling, with interval of $k=2$.

The collection took place from April 2013 to March 2014. Inclusion criteria were considered: to be 60 years or older; both sexes; no display of cognitive decline; and agree to participate in the study. Older adults with restriction to walk, due to surgery or surgical procedure, were interviewed on the following day. The exclusion criteria were: older adults who presented severe Cerebral Vascular Accident (CVA) sequelae, with loss in strength and aphasia; Parkinson's disease in severe or unstable stage, with association of serious compromises of motor skills, speech, or affection, which prevented the implementation of evaluations; older adults in terminal stage and with serious deficit of vision and hearing; older adults hospitalized again, interviewed earlier in the collection period; and older adults with restriction to walk and talk. In that period, 445 individuals were included, and 255 took part in this research ( 97 belonging to the medical clinic and 158 to the surgical clinic). Losses and exclusions were: refusals (75), cognitive decline without a companion (57), decline with PFEFFER equal to or greater than six (44), and other reasons (14).

Interviewers were selected, with prior experience, trained to fill data collection instruments and to approach the respondents. To this end, a research assistant, properly trained, chose older adults cared for in the HC, for implementation of the road map of the interview and other evaluations (anthropometric and physical performance measures). 
The data were collected, preferably in a private place, in the medical and surgical clinics of HC/UFTM. Systematic meetings were held between the researchers and interviewers, for training, attendance and guidance on the data collection.

Cognitive assessments were initially performed through the Mini Mental State Examination (MMSE). The cutoff point for cognitive decline considered the respondent's education level, corresponding to 13 points to illiterates, 18 points or fewer for those between one and 11 years of study and 26 points for schooling over 11 years $^{(14)}$. If the older adult presented cognitive decline in the MMSE evaluation, a companion was required, named informant, i.e., someone who knew information about the individual. The informants were subjected to the PFEFFER questionnaire(15). The application of PFEFFER, associated with the MMSE, indicates the presence of more serious cognitive decline when the score is equal to or greater than six points ${ }^{(15)}$. In this study, interview with the older adults was conducted when the result in PFEFFER was below six points, being the information supplemented, if necessary, by the informant, designated assistant. When the older adult presented final score equal to or greater than six the interview was finished.

To characterize sociodemographic data and variables related to hospitalization, we used an instrument prepared by the Public Health research group. The morbidities mentioned by the patient were considered and identified in the medical record, as well as the regular use of medicine and hospitalization evolution.

Individuals who roamed were submitted to anthropometric assessment by means of the following measures: body weight, height and calculation of the Body Mass Index (BMI), using the following equation: weight $(\mathrm{kg})$ divided by height $(\mathrm{m})$ squared $\left(\mathrm{kg} / \mathrm{m}^{2}\right)$. For those with inability to walk, the estimated weight and height was established according to the proposed formulas for hospitalized patients. To do so, brachial, waist and calf circumference as well as semi-span were measured(16).

We verified the presence of frailty syndrome through the five items described as components of frailty phenotype, proposed by Fried et al.(4): unintentional weight loss, evaluated through the following question: "In the last year, have you lost more than $4.5 \mathrm{~kg}$ without intention (i.e., without diet or exercise)?". Positive score was attributed to the frailty criterion when the weight loss report was greater than $4.5 \mathrm{~kg}$ in the last year, or more than $5 \%$ of body weight; decreased muscle strength was verified based on the grip strength, assessed by the manual hydraulic dynamometer JAMAR type, SAEHAN model ${ }^{\circledR}$. The examiner stimulated the patients through verbal command, in high volume, for them to pull the handle of the dynamometer with the dominant hand, keep it pressed for 6 seconds and then relax. Three measures were obtained, presented in $\mathrm{kg} /$ force (kgf), with an interval of one minute between them, being considered the average value of three measures and the cut-off points proposed by Fried et al.(4), adjusted for sex and Body Mass Index (BMI): men (BMI $\leq 24$, and grip strength $\leq 29 ;$ BMI 24.1-26, and grip strength $\leq 30$; BMI 26.1-28, and grip strength $\leq 30 ; B M I>28$, and grip strength $\leq 32)$ and women $(B M I \leq 23$, and grip strength $\leq 17$; BMI 23.1-26, and grip strength $\leq 17.3$; $B M I \leq 26.1-29$, and grip strength $\leq 18 ; B M I>29$, and grip strength $\leq 21)$; report of exhaustion and/or fatigue: measured through two questions of the Brazilian version of the Center for Epidemiological Studies depression (CES-D), items 7 ("felt that had to make efforts to take care of your usual tasks") and 20 ("failed to carry out your things"). Participants were questioned about how they felt in the previous week regarding the two questions and the answers were obtained in Likert scale ( $0=$ seldom or never, $1=$ sometimes, $2=$ often, and $3=$ always). Older adults who obtained score two or three in any one of the questions met the frailty criterion to this item ${ }^{(17)}$; slow speed: it was considered the running time (in seconds) spent to travel a distance of 4.6 meters. The individuals traveled a total distance of 8.6 meters, the first two and final two meters were disregarded for the calculation of the time spent on the march. Three measures were carried out, presented in seconds, considering the average of the three measurements. To do so, we used as standard a professional timer of the brand Vollo $^{\circledR}$, VL-1809 model and the cut-off points proposed by Fried et al.(4), adjusted for sex and height - men (height $\leq 173 \mathrm{~cm}$, and time $\geq 7$ seconds; height $>173 \mathrm{~cm}$, and time $\geq 6$ seconds) and women (height $\leq 159 \mathrm{~cm}$, and time $\geq 7$ seconds; height $>159 \mathrm{~cm}$, and time $\geq 6$ seconds); low physical activity level: verified through the long version of the International Physical activity Questionnaire (IPAQ), adapted for the older adults ${ }^{(18)}$. This questionnaire integrates questions related to physical activities performed in a usual week, with vigorous, moderate and light intensity, a minimum duration of 10 minutes, distributed in five areas: work, transportation, domestic activity, activity, leisure time/ recreation and sitting. The classification employed for this component followed the recommendations of the American College of Sports Medicine and the American Heart Association, which consider sufficiently active 
those who spend 150 minutes or more on weekly physical activity; and sufficiently inactive older adults who spend from zero to 149 minutes on weekly physical activity(19).

Individuals with three or more of these items were classified as frail, and those with one or two items, prefrail. Those with all negative tests for frailty syndrome were considered robust or not frail(4).

The socioeconomic and demographic variables of the study were: sex (male and female); age in years ( $60+70,70+80,80$ years or older); marital status (single, married or living common law, widowed or separated/divorced); home arrangement (living alone, with professional caregiver, spouse, with others of his generation, with children, grandchildren, daughter or son-in-law, other arrangements); schooling, in years of study (without education, $1-4 ; 4+8 ; 8$ or more); individual monthly income in minimum wages (without income, $<1 ; 1 ; 1\} 3 ; 3-5 ;>5 ;>5)$; number of medicines in regular use $(0,1\} 3 ; 3\} 5 ;>5)$; number of morbidities (none, 1 -3, 4 -7, 7 or more); evolution of hospitalization (death and the number of days of hospitalization); and ranking of frailty (frail, pre-frail or not frail).

After data collection an electronic, we built a database in the Excel program. The data were processed in a microcomputer, by 2 people, entered twice. We verified the existence of duplicate records and consistency of fields, due to wrong typing. If the data showed inconsistence, the original interview was resumed, for correction. For analysis, the database has been imported into the software Statistical Package for Social Sciences (SPSS), version 17.0.

Descriptive statistical analysis was performed for categorical variables, from absolute frequencies and percentages and measures of centrality (average) and dispersion (standard deviation) for numeric variables. To verify the association between the categorical variables the chi-square test was applied and, for the numeric,
ANOVA One-way with Post Hoc Dunnett T3 for multiple comparisons among groups $(p<0.05)$.

The project was submitted to the Committee of Ethics in Research with Human Beings of UFTM and approved under number 2511. The interviewers approached older adults in the HC-UFTM, presented the free and informed consent form, and after clarification of doubts requested them to sign it. Then, the interview began.

\section{Results}

Among the 255 respondents, the average age was 68.68 years $(S D= \pm 6.56)$, the majority was male, $60+70$ years, had 1 t 4 years of schooling and individual income of a minimum wage. The prevalence of frailty corresponded to $26.3 \%(n=67)$, while the pre-frailty represented $53.3 \%(n=136)$.

The proportion of 80 year-olds or more and widowers was higher among the frail older adults. Although there were no significant differences between the groups, among the frail, we verified a higher proportion of older women, without schooling and monthly individual income of a minimum wage. About housing arrangement, the highest percentage of frail older adults referred to occupation with children and grandchildren and the other ones with the spouse.

Table 1 (below) presents the socioeconomic and demographic variables, according to the state of frailty.

We did not observe significant differences between the groups for clinical variables, however, frail older adults presented a higher number of morbidities, used more medication and ended up dying. In multiple comparisons between the groups, frail older adults had higher average length of stay, compared to non-frail.

Table 2 (below) presents the clinical variables and evolution of hospitalization, according to the state of frailty.

Table 1 - Distribution of socioeconomic and demographic variables, according to the state of frailty. HC-UFTM. Uberaba, state of Minas Gerais, Brazil, 2013

\begin{tabular}{|c|c|c|c|c|c|c|c|c|c|}
\hline \multirow{2}{*}{ Variables } & \multicolumn{2}{|c|}{ Not frail } & \multicolumn{2}{|c|}{ Pre-frail } & \multicolumn{2}{|c|}{ Frail } & \multicolumn{2}{|c|}{ Total } & \multirow{2}{*}{$\mathbf{p}^{*}$} \\
\hline & $n$ & $\%$ & $n$ & $\%$ & $n$ & $\%$ & $n$ & $\%$ & \\
\hline Sex & & & & & & & & & 0.114 \\
\hline Male & 35 & 67.3 & 87 & 64 & 34 & 50.7 & 156 & 61.2 & \\
\hline Female & 17 & 32.7 & 49 & 36 & 33 & 49.3 & 99 & 38.8 & \\
\hline Age group & & & & & & & & & $0.004^{*}$ \\
\hline 60 - 70 & 38 & 73.1 & 84 & 61.8 & 35 & 52.2 & 157 & 61.8 & \\
\hline 70 으 80 & 13 & 25 & 46 & 33.8 & 20 & 29.9 & 79 & 31 & \\
\hline 80 or more & 1 & 1.9 & 6 & 4.4 & 12 & 17.9 & 19 & 7.5 & \\
\hline
\end{tabular}


Table 1 - (continuation)

\begin{tabular}{|c|c|c|c|c|c|c|c|c|c|}
\hline \multirow{2}{*}{ Variables } & \multicolumn{2}{|c|}{ Not frail } & \multicolumn{2}{|c|}{ Pre-frail } & \multicolumn{2}{|c|}{ Frail } & \multicolumn{2}{|c|}{ Total } & \multirow{2}{*}{$\mathbf{p}^{*}$} \\
\hline & n & $\%$ & $\mathbf{n}$ & $\%$ & n & $\%$ & $\mathbf{n}$ & $\%$ & \\
\hline Marital status & & & & & & & & & $0.035^{*}$ \\
\hline Single & 2 & 3.8 & 7 & 5.1 & 2 & 3 & 11 & 4.3 & \\
\hline Married & 32 & 61.5 & 92 & 67,6 & 32 & 47.8 & 156 & 61.2 & \\
\hline Widower & 12 & 23,1 & 19 & 14 & 24 & 35.8 & 55 & 21.6 & \\
\hline Separated & 6 & 11.5 & 18 & 13.2 & 9 & 13.4 & 33 & 12.9 & \\
\hline Housing arrangement & & & & & & & & & 0.056 \\
\hline Alone & 10 & 19.2 & 18 & 13.2 & 11 & 16.4 & 39 & 15.3 & \\
\hline Spouse & 17 & 32.7 & 47 & 34.6 & 16 & 23.9 & 80 & 31.4 & \\
\hline Spouse, children and grandchildren & 14 & 26.9 & 42 & 30.9 & 16 & 23.9 & 72 & 28.2 & \\
\hline Children and grandchildren & 8 & 15,4 & 16 & 11.8 & 21 & 31.3 & 45 & 17.6 & \\
\hline Other & 3 & 5.8 & 13 & 9.6 & 3 & 4.5 & 19 & 7.5 & \\
\hline Schooling (years) & & & & & & & & & 0.149 \\
\hline No schooling (years) & 6 & 11.5 & 27 & 20 & 18 & 26.9 & 51 & 20.1 & \\
\hline $1 \mid-4$ & 29 & 55.8 & 78 & 57.8 & 36 & 53.7 & 143 & 56.3 & \\
\hline 4 -8 & 9 & 17.3 & 22 & 16.3 & 6 & 9 & 37 & 14.6 & \\
\hline 9 or more & 8 & 15,4 & 8 & 5.9 & 7 & 10.4 & 23 & 9.1 & \\
\hline Monthly individual income ${ }^{\dagger}$ & & & & & & & & & 0.083 \\
\hline No income & 2 & 3.8 & 8 & 5.9 & 2 & 3 & 12 & 4.7 & \\
\hline$<1$ & - & - & 7 & 5.1 & 1 & 1.5 & 8 & 3.1 & \\
\hline 1 & 25 & 48.1 & 76 & 55.9 & 43 & 64.2 & 144 & 56.5 & \\
\hline $1-3$ & 21 & 40.4 & 38 & 27.9 & 21 & 31.3 & 80 & 31.4 & \\
\hline $3-5$ & 3 & 5.8 & 5 & 3.7 & - & - & 8 & 3.1 & \\
\hline$>5$ & 1 & 1.9 & 2 & 1.5 & - & - & 3 & 1.2 & \\
\hline
\end{tabular}

$* \mathrm{p}<0.05$

+ Minimum wage in Brazil in 2013 was $\mathrm{R} \$ 678.00$; in 2014 was $\mathrm{R} \$ 724.00$.

Table 2 - Distribution of clinical variables, according to the state of frailty. HC-UFTM. Uberaba, state of Minas Gerais, Brazil, 2013

\begin{tabular}{|c|c|c|c|c|c|c|c|c|c|}
\hline \multirow{2}{*}{ Variables } & \multicolumn{2}{|c|}{ Not frail } & \multicolumn{2}{|c|}{ Pre-frail } & \multicolumn{2}{|c|}{ Frail } & \multicolumn{2}{|c|}{ Total } & \multirow{2}{*}{$\mathbf{p}^{*}$} \\
\hline & $\mathbf{n}$ & $\%$ & $\mathrm{n}$ & $\%$ & $\mathbf{n}$ & $\%$ & $\mathbf{n}$ & $\%$ & \\
\hline Morbidities & & & & & & & & & 0.312 \\
\hline None & 2 & 3.8 & 1 & 0.7 & 1 & 1.5 & 4 & 1.6 & \\
\hline $1 \vdash 3$ & 12 & 23.1 & 52 & 38.2 & 19 & 28.4 & 83 & 32.5 & \\
\hline $4 \vdash 7$ & 19 & 36.5 & 38 & 27.9 & 19 & 28.4 & 76 & 29.8 & \\
\hline 7 or more & 19 & 36.5 & 45 & 33.1 & 28 & 41.8 & 92 & 36.1 & \\
\hline Use of medicines & & & & & & & & & 0.852 \\
\hline None & 2 & 3.8 & 6 & 4.4 & 1 & 1.5 & 9 & 3.5 & \\
\hline $1-3$ & 8 & 15.4 & 16 & 11.8 & 6 & 9 & 30 & 11.8 & \\
\hline $3-5$ & 9 & 17.3 & 24 & 17.6 & 12 & 17.9 & 45 & 17.6 & \\
\hline 5 or more & 33 & 63.5 & 90 & 66.2 & 48 & 71.6 & 171 & 67.1 & \\
\hline Death & & & & & & & & & 0.150 \\
\hline Yes & - & - & 5 & 3.7 & 3 & 4.5 & 8 & 3.1 & \\
\hline No & 52 & 20.4 & 131 & 96.3 & 64 & 95.5 & 247 & 96.9 & \\
\hline Inpatient days (average \pm SD) & \multicolumn{2}{|c|}{$7.4 \pm 7.5$} & \multicolumn{2}{|c|}{$10 \pm 8.5$} & \multicolumn{2}{|c|}{$12.8 \pm 11.4$} & \multicolumn{2}{|c|}{$10.25 \pm 9.3$} & $0.006^{*+}$ \\
\hline
\end{tabular}

$* \mathrm{p}<0.05$

+ Multiple comparisons among the groups: differences observed for frail older adults, compared to non-frail.

\section{Discussion}

The prevalence of frail older adults in this study was lower than the international investigation conducted in Belgium, which found $40 \%$ of frailty. This fact can be related to the local, since the research conducted in the geriatric aid room of a tertiary hospital and clipping of the study, which included people aged 70 years or more $^{(20)}$. The same was noted in an hospital institution in Passo Fundo, state of Rio Grande do Sul, that verified $46.5 \%$ of people in frail condition, despite the similar result for pre-frailty $(49.5 \%)^{(9)}$. 
Although the results are similar to studies conducted in the community for the pre-frailty condition ${ }^{(4,7)}$, the prevalence of frail older adults hospitalized was superior to these investigations ${ }^{(4,7)}$, suggesting the influence of the very process of hospitalization ${ }^{(10)}$. Furthermore, the reduction of capacity to respond to stress conditions and vulnerability, predispose frail older adults to chronic illnesses, anorexia, sarcopenia, osteopenia, cognitive deficit and inability, characteristics that may explain susceptibility to adverse outcomes such as hospitalization ${ }^{(3-4)}$.

This way, it should be noted that there have been suggested diagnosis and care models aiming to an early detection of the frail older adults and primary prevention of non-frail, to prevent the progression of the frame, in addition to complications, hospitalization time and readmissions ${ }^{(9)}$.

The highest proportion of 80 year old frail people is supported by a research conducted in a sector of clinical medicine in a tertiary hospital, with predominance of older adults in the presence of severe frailty ${ }^{(10)}$. This suggests that the influence of aging may predispose the frailty process ${ }^{(3-4)}$, with a probable increase in the use of health services and hospital admissions. However, the frailty should not be considered as a condition of aging, causing late decisions for appropriate interventions planning. This way, it would minimize the reversal potential of its consequences and reducing the prospect of healthy life without disabilities ${ }^{(10)}$.

It is important to emphasize that most of the older adults interviewed in this study were part of the age group between 60 and 70 years, similar findings in

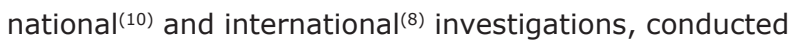
with hospitalized patients. So, it is relevant the attention directed to this age group, besides the identification of older adults in the embrittlement process in the pre hospitalization period, targeting health care according to their needs ${ }^{(9)}$.

The absence of differences in the relation between frailty and sex supports the research carried out in a hospital in Passo Fundo, state of Rio Grande do Sul,

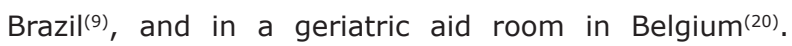
Despite this, the highest percentage of frail older women is supported by research conducted with older adults in clinical unit of a hospital in the city of Ribeirão Preto, state of São Paulo, Brazil(10), and in international investigation in Canada(21). The relationship between frailty and the female sex is supported by studies in the community ${ }^{(4,6-7,22)}$. It stood out that most of the older adults in this study were male, reflection of a more susceptible hospitalization, a consequence of the vulnerable attention to their health ${ }^{(9-10)}$. It is added to the possible condition the reason of hospitalization that could be more severe and incapacitating among men ${ }^{(9)}$.

Regarding to the highest proportion of frail older adults widowed, an inconsistent result was observed in a hospital investigation in Passo Fundo, with significant absence for the marital status variable and frailty levels ${ }^{(9)}$. A study conducted with older adults admitted to an intensive care unit in Canada verified the highest proportion of frail older adults among those who had not married or were widowers ${ }^{(21)}$. Considering that the spouse may represent support, due to greater closeness and bond, the support network among widows and widowers must be identified. Greater vulnerability and state of health deterioration ${ }^{(3-4)}$ require long-term care and social support ${ }^{(10)}$, being crucial that older adults have personal relationships. The health team can contribute by identifying this aspect along with the family, to foster shared care during the period of hospitalization and after discharge.

Concerning the housing arrangement, the highest percentage of frail older adults referred to occupation with children and grandchildren and the other ones with spouse. It is likely that the condition of frailty may be a reflection of greater demand for family care, justifying the presented results. In this sense, it is the role of the health team to identify the possible difficulties related to home care and develop educational activities for improvement of care.

In this investigation, we found a higher percentage of frail older adults without schooling and with monthly individual income of a minimum wage, although there is not a statistically significant association, consistent with international research, in a hospital setting ${ }^{(20)}$, to the schooling variable. Nevertheless, low level of education and income represent risk for the development of the frailty syndrome(22).

The association between frailty and chronic disease has been described in the scientific literature ${ }^{(6,22)}$. A study conducted with hospitalized older adults in geriatric unit found that the frail presented a higher average number of comorbidities ${ }^{(20)}$, indicating the relation between these two aspects. In this perspective, it is suggested that 
the condition of frailty may contribute to the advent of comorbidities, resulting in hospitalization. On the other hand, the hospital environment appears as a setting of acute conditions, and can exert influence on the high manifestation of this syndrome. Thus, it is necessary to supervise these conditions. On this subject, reference is made to health care system for older adults, at various levels of attention, emerging the need for preventive activities.

Although this investigation have not obtained relation between medication use and frailty, polypharmacy is considered a risk factor for this syndrome in older adults(23). A longitudinal study showed that American patients at baseline with higher scores used more medicine(24). Moreover, it is likely that the increased use of medication is a reflection of the manifestations of morbidities in the acute phase, considering that frail older adults, in this study, have presented a higher number of diseases, increasing the frailty in hospitals.

About the clinical evolution, inconsistent result was observed in a study conducted in Belgium with hospitalized patients, in which the death during hospitalization was associated with frailty ${ }^{(20)}$. Another highlight in this investigation: the deaths of only prefrail and frail older adults. It should be noted that the process of hospitalization has been related to mortality between frail states ${ }^{(25)}$.

The results of this study are supported by investigations with older adults populations in the medical clinic sectors ${ }^{(8)}$ and geriatric aid room ${ }^{(20)}$ on the highest average days of hospitalization among older adults in frail condition. This fact may be related, though not investigated, to the greater number of morbidities, which could encourage complications and recovery process. Hospital environments may compromise the functionality of older adults, making the recovery of the frail and pre-frailty states difficult ${ }^{(25)}$. This may reflect on the prolonged use of tertiary services. Thus, the need for actions to reduce hospitalizations for preventable causes and prevent its complications is apparent(25). It is known that the identification of older adults frailty condition at the time of admission can facilitate the planning of actions and therapeutic conduct by the multidisciplinary team ${ }^{(9)}$. So, the health team should monitor the recovery of the patients during hospitalization and at the time of hospital discharge. It is suggested that the screening of this condition after the high encourages of older adults care guidelines, maximizing the improvement of their health status.

\section{Conclusion}

The prevalence of frailty in hospitalized patients was elevated, and the proportion of frail older adults aged 80 years or older, widowed and with the highest average days of hospitalization, was higher when compared to other groups.

It should be noted that the prevalence of frailty, obtained in this investigation, was superior to studies with older adults from the community aspect that suggests health risk, implications for health services and overload of family care.

In this perspective, it is believed that the identification of health conditions in relation to the ones of pre-frailty and frailty can facilitate the planning and implementation of assistance to older adults in this context, considering the repercussions that come with this syndrome and the process of hospitalization.

Considering the scarcity of national studies, this research aims to contribute to expanding the knowledge of the socioeconomic and clinical factors related to frailty in hospitals. So, these data can subsidize actions in preventive health, directing the care, to delay their development. In this context, we stress the need for reflection on health system about of the attention system to older adults to meet the health needs of this population, at various levels of attention, considering the maximization of the harms to health arising from this syndrome.

Stands out, as a limitation of this research, the clipping, which did not allow the establishment of causality relations. The longitudinal investigations, in this scenario, are necessary for further consideration and to understand the genesis of this syndrome.

\section{References}

1. Clegg A, Young J, Iliffe S, Rikkert MO, Rockwood K. Frailty in elderly people. Lancet. 2013;381(9868):752-62. 2. Morley JE, Vellas B, van Kan GA, Anker SD, Bauer JM, Bernabei R, et al. Frailty consensus: a call to action. J Am Med Dir Assoc. 2013;14(6):392-7.

3. Fried LP, Ferrucci L, Darer J, Williamson JD, Anderson G. Untangling the concepts of disability, 
frailty, and comorbidity: implications for improved targenting and care. J Gerontol A Biol Sci Med Sci. 2004;59(3):255-63.

4. Fried LP, Tangen CM, Walston J, Newman AB, Hirsch C, Gottdiener J, et al. Frailty in older adults: evidence for a phenotype. J Gerontol A Biol Sci Med Sci. 2001;56(3):M146-56.

5. Walston J, Hadley EC, Ferrucci L, Guralnik JM, Newman AB, Studenski SA, et al. Research agenda for frailty in older adults: Toward a better understanding of physiology and etiology: Summary from the American Geriatrics Society/National Institute on Aging Research Conference on Frailty in Older Adults. J Am Geriatr Soc. 2006;54(6):991-1001.

6. Sánchez-García S, Sánchez-Arenas R, GarcíaPeña C, Rosas-Carrasco O, Avila-Funes JA, RuizArregui L, et al. Frailty among community-dwelling elderly Mexican people: prevalence and association with sociodemographic characteristics, health state and the use of health services. Geriatr Gerontol Int. 2013;14(2):395-402.

7. Neri $A L$, Yassuda MS, Araújo LF, Eulálio MC, Cabral BE, Siqueira MEC, et al. Metodologia e perfil sociodemográfico, cognitivo e de fragilidade de idosos comunitários de sete cidades brasileiras: Estudo FIBRA. Cad Saúde Pública. 2013;29(4):778-92.

8. Khandelwal D, Goel A, Kumar U, Gulati V, Narang R, Dey $A B$. Frailty is associated with longer hospital stay and increased mortality in hospitalized older patients. J Nutr Health Aging. 2012;16(8):732-5.

9. Oliveira DR, Bettinelli LA, Pasqualotti A, Corso D, Brock F, Erdmann AL. Prevalence of frailty syndrome in old people in a hospital institution. Rev. Latino-Am. Enfermagem. 2013; 21(4):891-8. [acesso 27 out 2014]; Disponível em: $\quad$ http://www.scielo.br/scielo.php?script=sci_ arttext\&pid $=$ S0104-11692013000400891\&lng =pt. http://dx.doi.org/10.1590/S0104-11692013000400009. 10. Storti LB, Fabrício-Whebe SCC, Kusumota L, Rodrigues RAP, Marques S. Fragilidade de idosos internados na clínica médica da unidade de emergência de um hospital geral terciário. Texto Contexto Enferm. 2013;22(2):452-9.

11. Makary MA, Segev DL, Pronovost PJ, Syin D, Bandeen-Roche K, Patel P, et al. Frailty as a predictor of surgical outcomes in older patients. J Am Coll Surg. $2010 ; 210(6): 901-8$.
12. Pilotto A, Rengo F, Marchionni N, Sancarlo D, Fontana A, Panza $F$, et al. Comparing the prognostic accuracy for all-cause mortality of frailty instruments: a multicentreyear follow-up in hospitalized older patients. PLoS One. 2012;7(1):e29090.

13. Purser JL, Kuchibhatla MN, Fillenbaum GG, Harding T, Peterson ED, Alexander KP. Identifying frailty in hospitalized older adults with significant coronary artery disease. J Am Geriatr Soc. 2006;54(11):1674-81.

14. Bertolucci PHF, Brucki SMD, Campacci SR, Juliano Y. Mini-exame do estado mental em uma população geral: impacto da escolaridade. Arq Neuro Psiquiatr. 1994;52(1):1-7.

15. Ministério da Saúde (BR). Secretaria de Atenção à Saúde. Departamento de Atenção Básica. Envelhecimento e saúde da pessoa idosa. Brasília: Ministério da Saúde; 2007. 192 p.

16. Rabito EI, Vannuchi GB, Suen VMM, Castilho Neto LL, Marchini JS. Weight and height prediction of immobilized patients. Rev Nutr. 2006;19(6):655-61.

17. Batistoni SST, Neri AL, Cupertino APFB. Validade da escala de depressão do Center for Epidemiological Studies entre idosos brasileiros. Rev Saúde Pública. 2007;41(4):598-605.

18. Benedetti TB, Mazo GZ, Barros MVG. Aplicação do questionário internacional de atividades físicas (IPAQ) para avaliação do nível de atividades físicas de mulheres idosas: validade concorrente e reprodutibilidade testereteste. Rev Bras Cienc Mov. 2004;12(1):25-33.

19. Pate RR, Pratt M, Blair SN, Haskell WL, Macera CA, Bouchard $C$, et al. Physical activity and public health. A recommendation from the Centers for Disease Control and Prevention and the American College of Sports Medicine. JAMA. 1995;273(5):402-7.

20. Joosten E, Demuynck M, Detroyer E, Milisen, K. Prevalence of frailty and its ability to predict in hospital delirium, falls, and 6-month mortality in hospitalized older patients. BMC Geriatr. 2014,14(1):1-9.

21. Bagshaw SM, Stelfox HT, McDermid RC, Rolfson DB, Tsuyuki RT, Baig N, et al. Association between frailty and short- and long-term outcomes among critically ill patients: a multicentre prospective cohort study. CMAJ. 2014;186(2):E95-102.

22. Mello AC, Engstrom EM, Alves LC. Fatores sociodemográficos e de saúde associados à fragilidade em idosos: uma revisão sistemática de literatura. Cad Saúde Pública. 2014;30(6):1143-68. 
23. Gnjidic D, Hilmer SN, Blyth FM, Naganathan $V$, Cumming RG, Handelsman DJ. High-risk prescribing and incidence of frailty among older community-dwelling men. Clin Pharmacol Ther. 2012;91(3):521-8.

24. Evans SJ, Sayers M, Mitnitski A, Rockwood K. The risk of adverse outcomes in hospitalized older patients in relation to a frailty index based on a comprehensive geriatric assessment. Age Ageing. 2014;43(1):127-32.

25. Gill TM, Gahbauer EA, Han L, Allore HG. The relationship between intervening hospitalizations and transitions between frailty states. J Gerontol A Biol Sci Med Sci. 2011; 66(11):1238-43. 